\title{
Energy-efficient design, consumer awareness, and public policy
}

\author{
Carmen Arguedas $^{1}(1) \cdot$ Sandra Rousseau $^{2}$ (1)
}

Received: 16 July 2020 / Accepted: 28 October 2020 / Published online: 27 November 2020

(C) The Author(s) 2020

\begin{abstract}
To facilitate the energy transition, regulators can choose between several policy options to stimulate energy-efficient design by firms. One possibility is to target firms directly through standards or subsidies. Alternatively, it is possible to influence firms indirectly by targeting firms' stakeholders and raising consumer awareness through information campaigns and education. In this paper, we focus specifically on the pivotal role of consumers and we investigate the effectiveness of subsidies, product standards, and education in improving firms' environmental performance through energy-efficient product design. In particular, we investigate the importance of the interaction effect between the regulation and consumers' environmental awareness under different market structures. We find that a policy based on a product standard can counteract the negative effects of crowding-out consumers' intrinsic motivation in a monopoly setting, although this counteracting effect is less powerful under a duopoly. However, a subsidy does not provide such a backup system and the full effect of crowding-out will be visible.
\end{abstract}

Keywords Environmental policy instruments · Energy-efficient design • Crowding-in/crowding-out · Consumer awareness

JEL Classification C72 $\cdot$ D43 $\cdot \mathrm{H} 23 \cdot \mathrm{L} 51 \cdot \mathrm{Q} 58$

The authors wish to thank two anonymous referees for very useful comments on an earlier version of the paper, as well as financial support from the Spanish Ministry of Economy and Competitiveness under research project ECO2017-82449-P.

$凶$ Carmen Arguedas

carmen.arguedas@uam.es

1 Department Economic Analysis, Autonomous University of Madrid, Madrid, Spain

2 Faculty of Economics and Business, KU Leuven, Leuven, Belgium 


\section{Introduction}

Citizens and governments are increasingly worried about satisfying societal needs without exceeding our planetary boundaries (Raworth 2017). Resource scarcity, climate change, and environmental concerns have stimulated companies and regulators to promote a move toward a decarbonized and sustainable economy. The energy transition plays a crucial role in this evolution as 'access to clean, affordable and reliable energy has been a cornerstone of the world's increasing prosperity and economic growth' (Chu and Majumdar 2012, p. 294) or as Peter Voser as CEO of Royal Dutch Shell said 'energy is the oxygen of the economy' (World Economic Forum 2012, p. 2). Core elements of the energy transition are decarbonization and decreasing energy demand. A wide variety of actions and policies are used, and needed, to facilitate this transition. In this paper, we focus on firms' decisions regarding energy-efficient product design.

Energy-efficient product design is closely related to the concepts of green design or eco-design, which aim at reducing the environmental impact of products, including the energy consumption throughout their entire life cycle while preserving a product's quality level (Fullerton and Wu 1998). Therefore, energy-efficient product design includes a focus on embodied energy in the good as well as energy consumption during the use phase (Rahimifard et al. 2010). As mentioned by Morini et al. (2019), embodied energy and carbon footprints are interesting indicators for selecting materials with a lower environmental burden during the product life cycle. The focus on energy efficiency during the use phase, on the other hand, has led to widespread concerns regarding rebound effects (Gillingham et al. 2016), and mitigation of these rebound effects is increasingly seen as a crucial aspect of energy policies (Vivanco et al. 2016).

The European Commission has acknowledged early on that there is a worldwide demand for more efficient products to reduce energy and resource consumption, which resulted in the implementation of the Eco-Design Directive ${ }^{1}$ in 2009 . This directive provides consistent EU-wide rules for improving the environmental performance of products, such as household appliances, and information and communication technologies. The EU legislation on eco-design and energy labeling is an effective tool for improving the environmental performance of products by setting mandatory minimum standards for their energy efficiency. This eliminates the least performing products from the market, significantly contributing to the EU's energy efficiency objective. As reported by the European Commission (2019), by 2020 this framework is estimated to deliver energy savings of around 154 Mtoe per year in primary energy, which translates into $€ 470$ savings per EU household per year on energy bills. The framework also contributes to energy security by reducing the import of energy into the EU by the equivalent of 1.1 billion barrels of oil each year, and it contributes to the mitigation of climate change by reducing $\mathrm{CO}_{2}$ emissions by 320 million tons annually.

Concerned stakeholders such as businesses, local authorities, and environmental NGOs support the European regulator's desire to impose minimum standards for energy efficiency for different product categories (e.g., Friends of the Earth 2010; EEB 2019). However, past studies have revealed that mandatory regulation and use of eco-

\footnotetext{
${ }^{1}$ Directive 2009/125/EC of the European Parliament and of the Council of 21 October 2009 establishing a framework for the setting of eco-design requirements for energy-related products.
} 
nomic incentives can crowd out voluntary action (e.g., Frey and Oberholzer-Gee 1997; Kreps 1997; Nyborg and Rege 2003; Underhill 2016). For example, the implementation of a monetary reward system can actually reduce volunteering, even though — once implemented - the size of rewards increases volunteering (Frey and Götte 1999). Thus, stakeholders' awareness can influence, or be influenced by, regulation.

Political scientists are well aware that shifts in public opinion can lead to policy shifts (Hakhverdian 2012). For example, Anderson et al. (2017) show that as public opinion shifts toward prioritizing the environment, a significant and positive effect on the rate of renewable energy policy outputs by governments in Europe can be found. However, the opinion-policy link can work in both ways as politicians can also influence public opinion (Hakhverdian 2012). Democratic leadership occurs when the public's policy preferences align with the government's preferences (Geer 1996), while the counter-movement claims that public opinion may run counter to government policy in certain instances (Wlezien and Soroka 2012). Thus, while opinion and policy may move together in some policy domains, this is not necessarily the case for all domains. Positive as well as negative feedbacks between public opinion and policy may exist. For example, Stadelmann-Steffen and Eder (2020) investigate the link between existing domestic energy policies and individual policy instrument preferences in 21 European countries. While they do not find evidence of a general link between existing policies and future policy preferences, they do find that individuals with strong climate change attitudes and high levels of political trust experience positive feedback effects. As another example of a positive feedback, several studies on renewable energy infrastructure found that the public's opposition toward wind parks or high voltage lines decreased with real-life experience and exposure (e.g., Firestone et al. 2012; Olson-Hazboun et al. 2016). On the other hand, Stokes (2013) found a negative feedback in the case of Ontario's feed-in tariff policies which was mainly driven by expected future energy costs.

In this paper, we investigate how firms' incentives for energy-efficient design are affected by these interactions between consumers' awareness and public policy. Explicitly accounting for such interactions is crucial because they are sensitive to the policy instruments used. Regulators can choose between several policy options in order to stimulate energy-efficient design by firms. Instruments can target firms directly through standards or subsidies; or they can influence firms indirectly by targeting firms' stakeholders and raising consumer awareness through information campaigns and education. While the first option seems to target firms directly, it can also generate an indirect effect through its impact on consumer awareness. On the one hand, consumers can perceive the regulatory action as a signal of the seriousness of the societal problem, and consequently, they can decide to reward firms' efforts toward increasing energy efficiency more than before. On the other hand, social norms can be crowded out by the regulatory action, which may lead to lower social pressure by consumers.

Specifically, we analyze the pivotal role of consumers on the effectiveness of subsidies, product standards, and education in improving firms' environmental performance through energy-efficient product design. In particular, we investigate the importance of the interaction effect between the regulation and consumers' environmental awareness. To this end, we first consider a base model where a monopolist chooses prices and product energy efficiency under four different scenarios: (1) a 
baseline laissez-faire scenario, (2) an education-based policy, (3) a product standard, and (4) a technology subsidy. While crowding-in effects reinforce the policy effectiveness and may even incentivize over-compliance, the net effect of crowding-out is ambiguous. Next, we investigate the impact of competition on these results by looking at a model of product differentiation where two firms take simultaneous decisions on prices and product energy efficiency. We find that competition decreases the average level of product energy efficiency in the market as well as the prices. The net effects of crowding-out very much depend on the type of policy instrument used, but in general, we can conclude that the counteracting effects of the regulatory standard on crowding-out are less powerful than under monopoly. Finally, for completeness, we change the timing of the duopoly game and allow firms to first select the energy efficiency level of the product and then decide on the prices. This leads to a higher degree of product differentiation and may even stimulate one of the firms to be more energy-efficient than in a monopoly situation. Counteracting effects of the regulatory policy are also present under this alternative formulation.

Our paper is close to the literature on environmental policy in product differentiation models, but the main difference in our setting is that we model consumer awareness to depend on the stringency of the regulatory policy, while the related studies consider the two variables as being independent from each other. One of the most related studies is Moraga-Gonzalez and Padron-Fumero (2002), who analyze a duopoly setting in a vertical product differentiation model. Firms simultaneously decide on the production technology (being cleaner or dirtier) in the first stage, and they compete in prices in the second stage. In equilibrium, a cleaner and a dirtier variant coexist, and a maximum unit emission standard reduces unit emissions of both variants and thus boosts firms' sales with negative impacts on aggregate emissions. Besides the addition of crowdingin and crowding-out effects on this analysis, we study an alternative timing where the two firms take simultaneous decisions on prices and product energy efficiency. In this setting, we find the opposite effect to the one found in Moraga-González and Padrón-Fumero (2002). While the imposition of the standard causes an effect in the same direction on both firms in the model of sequential moves, in the model of simultaneous moves we find opposing effects that diminish differentiation and end up in zero prices. Hence, the timing of decisions becomes crucial regarding the effectiveness of environmental policy stringency.

Other related works are Espinola-Arredondo and Zhao (2012), who investigate how a tax/subsidy policy can promote the consumption of green products in the context of horizontal product differentiation; Casino and Granero (2018), who model the market entry decision as well as the product differentiation decision in a spokes model with a large number of potential varieties; or Rodriguez Ibeas (2007), who consider a vertical differentiation model to analyze the effect of (exogenous) changes in consumer awareness on social welfare. However, none of these studies analyze the changes in consumer awareness as a result of changes in the stringency of the environmental policy.

We organize the remainder of the paper as follows. We describe the base monopoly model in the following section. In Sect. 3, we present the results under different scenarios. In Sect. 4, we consider two versions of a duopoly model (one with simultaneous decisions and the other with sequential choices), and we compare the results with 
those obtained in Sect. 3. We conclude in Sect. 5. All the proofs are in a mathematical 'Appendix.'

\section{Base model}

We assume that a monopolist produces a consumption good characterized by some environmental features. (We will add competition at a later stage.) The firm can decide on the unit price $p$, as well as on the environmental attribute, or energy efficiency, of the product, $g$. For example, $g$ can reflect the energy needed during the use phase (e.g., fuel efficiency of a car) or the level of embedded carbon. We assume that the energy efficiency level of the product does not affect the unit production cost (assumed to be zero, for simplicity), but it will affect the firm's remaining operation costs, denoted as $c(g)=\frac{\alpha}{2} g^{2}$, with $\alpha>0 .^{2}$

The demand for the product is characterized by a mass of consumers that differ with respect to their initial willingness to pay for the environmental features. The willingness to purchase energy-efficient products is denoted as $\gamma$, and we assume that it is uniformly distributed in the interval $[\bar{\gamma}-L, \bar{\gamma}]$, with $L \in(0, \bar{\gamma})$. We assume that each consumer can buy at most one unit of the product. Consumers' (indirect) utility from consuming the product depends positively on the energy efficiency $g$ and negatively on the unit price $p$, as follows:

$$
U=\gamma g-p
$$

while consumers' reservation utility from not purchasing the product is assumed to be zero.

In order to stimulate energy-efficient design, the regulator has several options, and here we focus on three policy alternatives. Firstly, the regulator can directly increase consumers' awareness about the environmental impact of consumption choices and the importance to adopt a sustainable lifestyle (that is, increase $\bar{\gamma}$ ) through educational campaigns. ${ }^{3}$ Secondly, the regulator can opt for a centralized approach by imposing a product standard $\bar{g}$, which may force the firm to supply products that are more energy efficient. ${ }^{4}$ Thirdly, the regulator can provide a technology subsidy $s$ for the firm to stimulate the production of products that are more energy efficient.

\footnotetext{
2 Moraga-Gonzalez and Padron-Fumero (2002) also assume that the environmental attribute does not affect the unit production costs. This is obviously a simplification of reality, but it helps us to make the model tractable, particularly in the duopoly cases that we analyze later on.

3 The idea that information provision may have positive externalities is an important argument in favor of public support for education: Educating people may lead them to participate in activities that have external benefits (Kennedy et al. 1994). In this paper, we adhere to this idea. However, in contexts of asymmetric information about the severity of an environmental problem (not considered in this paper), Asheim (2010) shows that moral motivation provides a rationale for skepticism toward government information provision (such as climate change skepticism). Thus, unless the government can make a credible commitment to always share all available information, the problem cannot be solved simply by promising to be unbiased in the information provision, as citizens cannot verify whether the promise is being kept (Nyborg 2018).

4 For example, the firm may be required to use a minimum amount of decarbonized material, or to implement maximum limits to (passive) standby and off-mode power use for electrical appliances (e.g., to comply with the EU Eco-Design Directive 2009/125/EC).
} 
The first policy option directly increases consumer awareness $\bar{\gamma}$. However, the product standard and the technology subsidy can have an indirect impact on consumer awareness, which can be positive or negative. For example, consumers can interpret the presence of an environmental policy as a signal of the seriousness of the societal problem, which may make them more aware of the impact of their consumption decisions and increase $\bar{\gamma}$. We label this process as 'crowding-in.' Or, as another example, the presence of a regulation may decrease intrinsic incentives to buy energy-efficient products and may thus decrease $\bar{\gamma}$. This is labeled as the 'crowding-out' effect. In the following section, we describe in detail the consequences of these effects on the performance of the different environmental policy options.

\section{Results}

For presentation purposes, we first analyze the firm's problem in the absence of any intervention. Then, we study the performance of the three different policy scenarios described above, and we discuss the mentioned crowding effects.

\subsection{Firm behavior under laissez-faire}

Given the indirect utility function presented in (1) and zero reservation utility, a consumer with marginal willingness to pay for energy efficiency $\gamma$ purchases the product as long as $\gamma g \geq p$. Thus, only consumers with $\gamma \geq \frac{p}{g}$ are willing to purchase the product. Conversely, consumers with $\gamma<\frac{p}{g}$ do not purchase the product. Since $\gamma$ is uniformly distributed in the interval $[\bar{\gamma}-L, \bar{\gamma}]$, the aggregate demand for a product with energy efficiency level $g$ and unit price $p$ is:

$$
Q=\bar{\gamma}-\frac{p}{g}
$$

The objective of the monopolist is to find the product price $p$ and energy efficiency level $g$ to maximize profits $\pi$ as follows:

$$
\max _{p, g} \pi=p Q-c(g)=p\left(\bar{\gamma}-\frac{p}{g}\right)-\frac{\alpha}{2} g^{2}
$$

The following first-order conditions characterize the solution of this problem:

$$
\begin{aligned}
& \frac{\partial \pi}{\partial p}=\bar{\gamma}-\frac{2 p}{g}=0 \\
& \frac{\partial \pi}{\partial g}=\left(\frac{p}{g}\right)^{2}-\alpha g=0
\end{aligned}
$$

from which we easily obtain the optimal solution, summarized next. 
Proposition 1 In the absence of any policy intervention, the monopolist's optimal choices of the product price and energy efficiency level are, respectively, $p^{M}=\frac{\bar{\gamma}^{3}}{8 \alpha}$ and $g^{M}=\frac{\bar{\gamma}^{2}}{4 \alpha}$.

Clearly, both choice variables are increasing in consumers' awareness $\bar{\gamma}$ and decreasing in the parameter that reflects the cost of producing more energy-efficient products, $\alpha$. Substituting the optimal solution into the aggregate demand, firm's profits, and consumers' surplus $\left(C S^{M}\right)$, we, respectively, obtain:

$$
\begin{aligned}
& Q^{M}=\bar{\gamma}-\frac{p^{M}}{g^{M}}=Q=\bar{\gamma}-\frac{\bar{\gamma}}{2}=\frac{\bar{\gamma}}{2} \\
& \pi^{M}=p^{M} Q^{M}-\frac{\alpha}{2}\left(g^{M}\right)^{2}=\frac{\bar{\gamma}^{4}}{32 \alpha} \\
& \mathrm{CS}^{M}=\int_{\bar{\gamma} / 2}^{\bar{\gamma}}\left(\gamma g^{M}-p^{M}\right) \mathrm{d} \gamma=\int_{\bar{\gamma} / 2}\left(\gamma \frac{\bar{\gamma}^{2}}{4 \alpha}-\frac{\bar{\gamma}^{3}}{8 \alpha}\right) \mathrm{d} \gamma=\frac{\bar{\gamma}^{4}}{32 \alpha} .
\end{aligned}
$$

Note that the aggregate demand, firm's profits, and consumers' surplus are affected by consumers' awareness and production costs in the same way: The three functions increase with consumer awareness, $\bar{\gamma}$, and decrease with the cost of energy efficiency, $\alpha$.

\subsection{Policy scenarios}

We now study the monopolist's optimal choices under three policy scenarios: (i) raising consumers' awareness through educational campaigns; (ii) imposing a product standard; and (iii) giving a subsidy for investing in an energy-efficient production technology. The second and third possibilities may give rise to crowding effects, and we discuss the various possibilities.

\subsubsection{Raising awareness}

The results in Proposition 1 suggest that raising $\bar{\gamma}$ (through educational campaigns or advertising) has a direct effect on both the price and the energy efficiency level of the product. A more conscious population will induce the monopolist to increase the energy efficiency level of the product and charge a larger price. Raising $\bar{\gamma}$ also results in increases in aggregate demand $\left(Q^{M}\right)$, firm's profits $\left(\pi^{M}\right)$, and consumers' surplus $\left(\mathrm{CS}^{M}\right)$.

\subsubsection{Product standard}

Now, we assume that the government decides to implement a standard on the energy efficiency level of the firm, $\bar{g}$. The problem the monopolist solves is the following ${ }^{5}$ :

\footnotetext{
5 Throughout the paper, we assume perfect compliance. Hence, our results reflect the upper-bound impact of the different policy approaches.
} 


$$
\begin{aligned}
& \max _{p, g} \pi=p Q-c(g)=p\left(\bar{\gamma}-\frac{p}{g}\right)-\frac{\alpha}{2} g^{2}, \\
& \text { s.t. } g \geq \bar{g},
\end{aligned}
$$

and the result is provided next.

Proposition 2 Under a product standard $\bar{g}$, the monopolist's solution is the following:

(i) If $\frac{\bar{\gamma}^{2}}{4 \alpha} \geq \bar{g}$, then $p^{M}=\frac{\bar{\gamma}^{3}}{8 \alpha}$ and $g^{M}=\frac{\bar{\gamma}^{2}}{4 \alpha}$.

(ii) If $\frac{\bar{\gamma}^{2}}{4 \alpha}<\bar{g}$, then $p^{M}=\frac{\bar{\gamma}}{2} \bar{g}$ and $g^{M}=\bar{g}$.

Given that consumers value energy efficiency, the monopolist over-complies with the product standard as long as the level set by the regulator is small enough (case i). Alternatively, the monopolist just complies with the standard (case ii). This result is illustrated in Fig. 1, where we present the monopolist's optimal choices for the price and the energy efficiency level for the different values of the product standard, $\bar{g}$. The result in Proposition 1 (laissez-faire) corresponds to the particular case where $\bar{g}=0$ in Fig. 1. Since there exists a demand for energy efficiency, the monopolist finds it optimal to present more stringent attributes than those required by the law, as long as the requirements are lax enough. Obviously, when the law becomes more demanding than the business-as-usual level, the firm decides to just comply with the standard, and the induced price increases with $\bar{g}$.

In the context of a product standard, crowding-in and crowding-out effects may arise. Crowding-in refers to a rise in consumers' awareness once the product standard

Fig. 1 Product standards without crowding effects

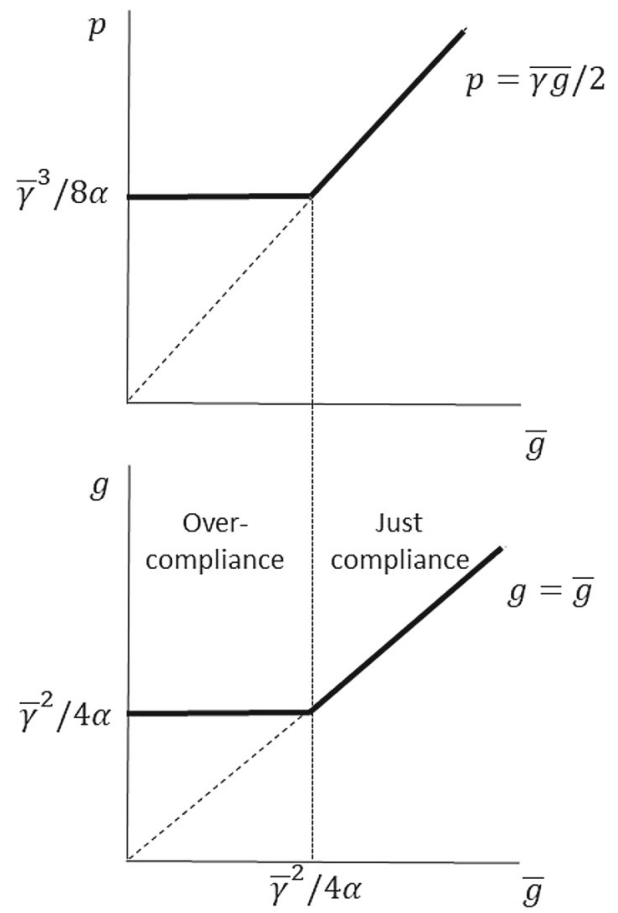


Fig. 2 Product standards with crowding-out

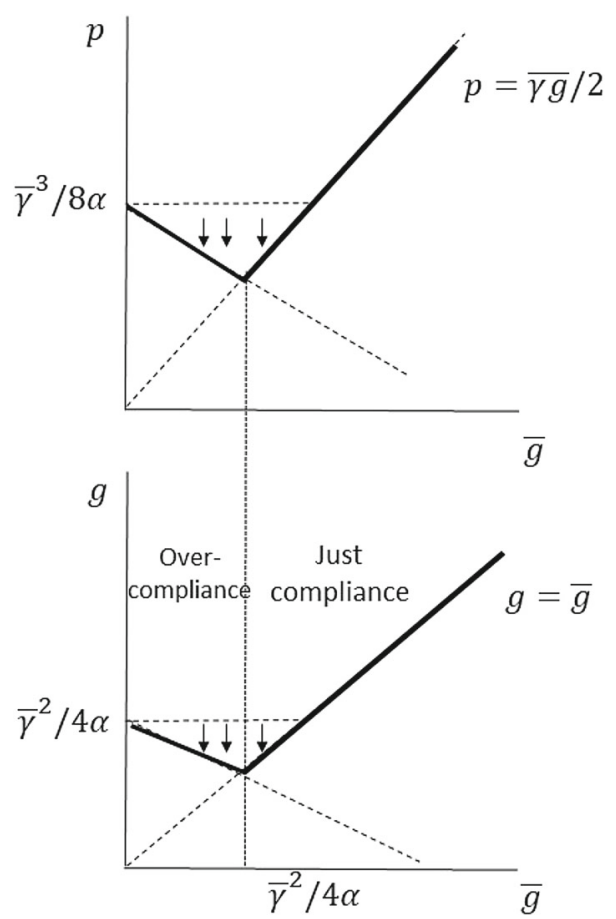

is in place. The way to model this effect is by assuming that $\bar{\gamma}$ is an increasing function of $\bar{g}$. If this is the case, the effect of the product standard is reinforced and production will become even more energy efficient. However, there can be situations where the presence of a product standard induces crowding-out. For example, consumers may complain about the price increase induced by the regulatory measure as they may be concerned by their daily cost of living (e.g., Sterner 2012; Ribot 2013). In this case, the final effect may be lower than expected. This is illustrated in Fig. 2, where we assume that $\bar{\gamma}$ is a decreasing function of $\bar{g}$. As a result of the decrease in function $\bar{\gamma}^{2} / 4 \alpha$ as long as $\bar{g}$ increases, the monopolist decreases the optimal energy efficiency level in the region of over-compliance (with the corresponding decrease in the product price), and the region itself shrinks, as compared to the region of just compliance, which remains unchanged.

\subsubsection{Technology subsidy}

The results in Proposition 1 suggest that a technology subsidy (represented by a decrease in parameter $\alpha$ ) causes an increase in both the energy efficiency level and the product price. These effects are illustrated in Fig. 3. Now, while the presence of crowding-in surely reinforces the effect of the technology subsidy causing further increases in both choice variables, the presence of crowding-out might create some ambiguities. If we assume that $\bar{\gamma}$ is an increasing function of $\alpha$, meaning that the lower the value of $\alpha$ (or the larger the amount of the subsidy) the lower the consumer aware- 
Fig. 3 Technology subsidy without crowding effects

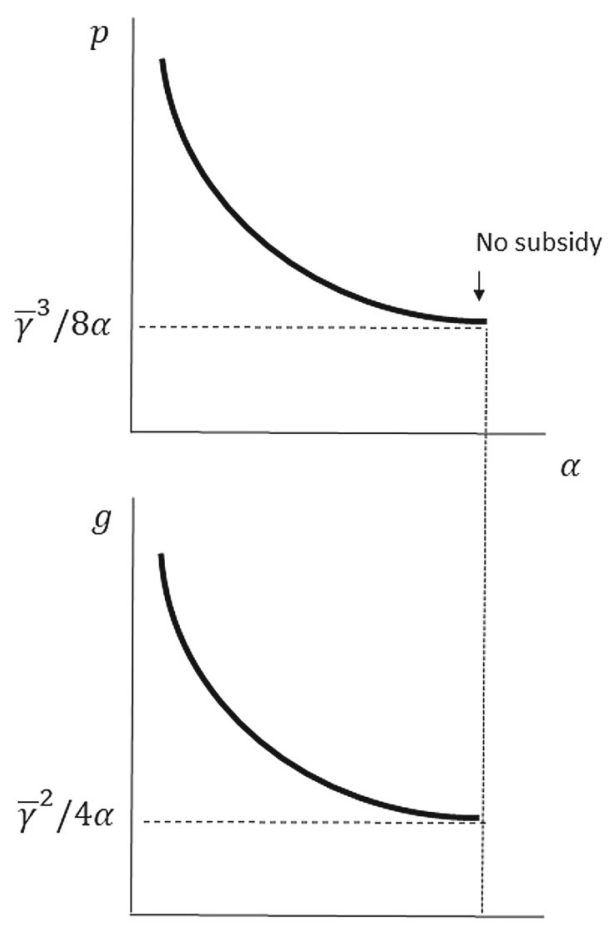

$\alpha$

ness $\bar{\gamma}$, then a marginal decrease in $\alpha$ causes the following effect on energy efficiency (there is a qualitatively similar effect on the price):

$$
\frac{\mathrm{d} g}{\mathrm{~d} \alpha}=\frac{\partial g}{\partial \alpha}+\frac{\partial g}{\partial \bar{\gamma}} \cdot \bar{\gamma}^{\prime}(\alpha) .
$$

The first term of the derivative is negative (see Proposition 1), which means that a marginal decrease in parameter $\alpha$ causes an increase in energy efficiency, $g$. Note, however, that the second term of the derivative is positive under crowding-out. (The effect of $\bar{\gamma}$ on $g$ is positive, and the effect of $\alpha$ on $\bar{\gamma}$ is positive as well.) Hence, as long as $\alpha$ decreases, it is not clear at all whether the net effect on the energy efficiency level is positive or negative, and the answer critically depends on the assumption we make on the specific relation between $\bar{\gamma}$ and $\alpha$, which is an empirical issue. Indeed, it is not difficult to construct examples where the final outcome can go in either direction. Figure 4 illustrates a situation where the presence of crowding-out can be very detrimental: In this case, imposing a subsidy is not recommended at all. ${ }^{6}$

\footnotetext{
6 The case of the figure can be obtained if we assume a function $\bar{\gamma}=\xi \alpha$ to account for crowding-out. Substituting this expression into the optimal energy-efficient level presented in Proposition 1, we obtain $g^{M}=\frac{\xi^{2} \alpha}{4}$. In this case, the imposition of a subsidy (represented by a decrease in $\alpha$ ) causes a decrease in energy efficiency as well as in the price of the product. As another example, we can instead assume $\bar{\gamma}=\xi \alpha^{1 / 4}$, which results in $g^{M}=\frac{\xi^{2}}{4 \alpha^{1 / 2}}$. Here, the subsidy (i.e., a decrease in $\alpha$ ) causes an increase in 
Fig. 4 Technology subsidy with crowding-out

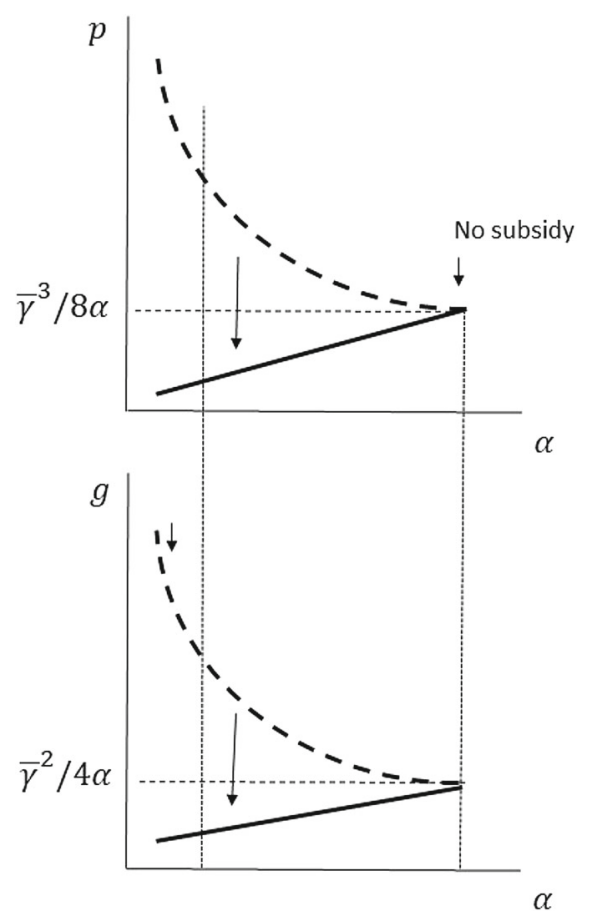

From the analyses above, and by comparing Figs. 2 and 4, we can conclude that although a product standard can avoid the detrimental effects of crowding-out, this may not be the case if a technology subsidy is in place. In fact, the case of Fig. 4 is telling us that there might be circumstances where giving a technology subsidy ends up having the opposite effect to the expected one. A product standard has a mandatory dimension that forces the firm to improve its energy efficiency, while a technology subsidy has a voluntary dimension as the firm does not have to use the subsidy to improve its energy efficiency. Our analysis then suggests caution in the use of subsidies when crowding-out is present.

\section{Adding competition}

In this section, we extend our model to allow for competition between two (ex ante) identical firms. We consider two alternative timings. First, we assume that the two firms decide prices and energy efficiency levels simultaneously. In an alternative scenario, we assume that the two firms choose energy efficiency levels in the first place, and they later choose prices contingent on the previously chosen energy efficiency levels. This second scenario is the one assumed in Moraga-Gonzalez and Padron-Fumero (2002)

Footnote 6 continued

both energy efficiency and the price, although the effects are softer than in the absence of crowding-out. In this case, the counteracting effect of crowding-out does not fully compensate the positive effect of the technology subsidy and the net effects on prices and energy efficiency are still positive. 
and may represent a situation where the costs associated with the energy efficiency level $g$ are mainly installation (or setup) costs. In this case, the choice of energy efficiency levels is considered as a long-term decision.

\subsection{Simultaneous choices under laissez-faire}

Two firms, 1 and 2, decide on the price and energy efficiency levels simultaneously. We denote these choice variables, respectively, as $\left(p_{1}, g_{1}\right)$ and $\left(p_{2}, g_{2}\right)$. Without loss of generality, we assume $p_{1}>p_{2}$ and $g_{1}>g_{2}$. Now, consumers choose between purchasing one unit of the product from firm 1 or from firm 2, or not purchasing any good. Consumers prefer buying from firm 1 over firm 2 as long as $\gamma g_{1}-p_{1} \geq \gamma g_{2}-p_{2}$, which results in the following aggregate demand for variety 1 :

$$
Q_{1}=\bar{\gamma}-\frac{p_{1}-p_{2}}{g_{1}-g_{2}} .
$$

Correspondingly, the aggregate demand for firm 2 is composed by the consumers that prefer variety 2 over variety 1 (i.e., those for which $\gamma g_{1}-p_{1}<\gamma g_{2}-p_{2}$ ), as long as they prefer purchasing from firm 2 to not purchasing at all (i.e., $\gamma g_{2}-p_{2} \geq 0$ ). This results in the following demand for variety 2 :

$$
Q_{2}=\frac{p_{1}-p_{2}}{g_{1}-g_{2}}-\frac{p_{2}}{g_{2}}=\frac{p_{1} g_{2}-p_{2} g_{1}}{g_{2}\left(g_{1}-g_{2}\right)} .
$$

The profit functions for the two firms are therefore:

$$
\begin{aligned}
& \pi_{1}=p_{1} Q_{1}-\frac{\alpha}{2} g_{1}^{2}=p_{1}\left(\bar{\gamma}-\frac{p_{1}-p_{2}}{g_{1}-g_{2}}\right)-\frac{\alpha}{2} g_{1}^{2} \\
& \pi_{2}=p_{2} Q_{2}-\frac{\alpha}{2} g_{2}^{2}=p_{2}\left(\frac{p_{1} g_{2}-p_{2} g_{1}}{g_{2}\left(g_{1}-g_{2}\right)}\right)-\frac{\alpha}{2} g_{2}^{2}
\end{aligned}
$$

Each firm finds its corresponding price and energy efficiency level to maximize its own profits, taking the choices of the rival firm as given. We present the result of this simultaneous game in the following proposition. The proof can be found in the 'Appendix.'

Proposition 3 In the absence of any policy intervention, the duopolists' optimal choices of the product price and energy efficiency level under simultaneous moves are, respectively, $p_{1}^{D}=\frac{0,091 \bar{\gamma}^{3}}{\alpha}, g_{1}^{D}=\frac{0,24 \bar{\gamma}^{2}}{\alpha}, p_{2}^{D}=\frac{0,013 \bar{\gamma}^{3}}{\alpha}$ and $g_{2}^{D}=\frac{0,07 \bar{\gamma}^{2}}{\alpha}$.

This duopoly case leads to product differentiation based on the level of product energy efficiency. Firm 1 targets consumers with a high appreciation of the firm's effort to reduce the environmental impact of production, while firm 2 targets those consumers with a low appreciation for such efforts. Comparing the duopoly outcomes with the monopoly outcomes (Proposition 3 vs. Proposition 1), we find that introducing competition in the product market reduces both firms' incentives to invest in 
energy-efficient design $\left(g_{2}^{D}<g_{1}^{D}<g^{M}\right)$ as the amount of rents they can capture from consumers decreases and also prices decrease $\left(p_{2}^{D}<p_{1}^{D}<p^{M}\right)$. This is in line with the findings from Moraga-Gonzalez and Padron-Fumero (2002), who find that a cleaner and a dirtier variant coexist in equilibrium when buyers have a different willingness to pay for products, with a reduced environmental impact.

We now substitute these results to obtain aggregate quantities and firms' profits:

$$
\begin{aligned}
& Q_{1}^{D}=\bar{\gamma}-\frac{\frac{0,078 \bar{\gamma}^{3}}{\alpha}}{\frac{0,17 \bar{\gamma}^{2}}{\alpha}}=0,54 \bar{\gamma} \\
& Q_{2}^{D}=\frac{p_{1} g_{2}-p_{2} g_{1}}{g_{2}\left(g_{1}-g_{2}\right)}=\frac{\frac{0,091 \bar{\gamma}^{3}}{\alpha} \frac{0,07 \bar{\gamma}^{2}}{\alpha}-\frac{0,013 \bar{\gamma}^{3}}{\alpha} \frac{0,24 \bar{\gamma}^{2}}{\alpha}}{\frac{0,07 \bar{\gamma}^{2}}{\alpha}\left(\frac{0,17 \bar{\gamma}^{2}}{\alpha}\right)}=0,27 \bar{\gamma} \\
& \pi_{1}^{D}=\frac{0,091 \bar{\gamma}^{3}}{\alpha} 0,54 \bar{\gamma}-\frac{\alpha}{2}\left(\frac{0,24 \bar{\gamma}^{2}}{\alpha}\right)^{2}=\frac{0,02 \bar{\gamma}^{4}}{\alpha}<\pi^{M} \\
& \pi_{2}^{D}=\frac{0,013 \bar{\gamma}^{3}}{\alpha} 0,27 \bar{\gamma}-\frac{\alpha}{2}\left(0,07 \frac{\bar{\gamma}^{2}}{\alpha}\right)^{2}=\frac{0,001 \bar{\gamma}^{4}}{\alpha}<\pi^{M}
\end{aligned}
$$

As expected, competition leads to lower profits for the firms in the market.

\subsection{Sequential choices under laissez-faire}

In the context of the same duopoly, we change the timing of the decisions and we consider that firms first choose the energy efficiency level simultaneously, and, in a second stage, they choose the price simultaneously. The solution to this alternative problem is presented next. The proof can be found in the 'Appendix.'

Proposition 4 In the absence of any policy intervention, the duopolists' optimal choices of the product price and energy efficiency level under sequential moves are, respectively, $p_{1}^{S}=\frac{0,11 \bar{\gamma}^{3}}{\alpha}, g_{1}^{S}=\frac{0,26 \bar{\gamma}^{2}}{\alpha}, p_{2}^{S}=\frac{0,01 \bar{\gamma}^{3}}{\alpha}$ and $g_{2}^{S}=\frac{0,05 \bar{\gamma}^{2}}{\alpha}$.

Again, product differentiation occurs, and a more and a less energy-efficient product are available in equilibrium. Comparing the level of product energy efficiency in a duopoly with sequential moves (denoted by superscript ' $S$ ') with the results of a duopoly with simultaneous moves (denoted by superscript 'D') and the monopoly results (denoted by superscript ' $M$ ') leads to the following ranking for firm 1 and 2 , respectively:

$$
\begin{aligned}
& g_{1}^{D}<g^{M}<g_{1}^{S} \\
& g_{2}^{S}<g_{2}^{D}<g^{M}
\end{aligned}
$$

Changing the timing of the duopoly game has two interesting consequences. Firstly, the degree of product differentiation with sequential energy efficiency and price decisions increases compared to the degree of product differentiation with simultaneously 
decisions. Secondly, firm 1 now invests more in energy-efficient design than even a monopolist would. Interestingly, the price firm 1 sets is below the monopolistic price, even when the energy efficiency level that this duopolist chooses is above the monopolistic level.

\subsection{Policy scenarios}

We now look at the impact of the three different policy scenarios on incentives for energy-efficient design in the duopoly model.

\subsubsection{Raising awareness}

In Propositions 3 and 4, we have shown that $\bar{\gamma}$ has a direct effect on both the price and the energy efficiency level of the two varieties of the product. Therefore, increases in $\bar{\gamma}$ (through educational campaigns or marketing) will induce the two firms to increase the energy efficiency level of the product and charge a larger price. The ranking of prices and energy efficiency levels and the comparison with respect to the monopoly case remain the same in the two scenarios for any value of $\bar{\gamma}$. However, as long as $\bar{\gamma}$ increases, the differences between the respective levels also increase.

\subsubsection{Product standard}

We now consider a product standard imposed on the energy efficiency level of the firms, $\bar{g}$. Taking the case of simultaneous choices, the problem is interesting only when the required level is larger than the energy efficiency level of firm 2 in the absence of any intervention, that is, $\bar{g} \geq g_{2}^{D}=\frac{0,07 \bar{\gamma}^{2}}{\alpha}$. Otherwise, the product standard is non-binding and firms simply choose their laissez-faire levels (see Proposition 3). However, when the government requires a more demanding standard, firm 2 just complies with it, and this has an indirect effect on firm 1, due to the strategic interaction between the two firms. The proof of this result is in the 'Appendix.'

Proposition 5 Under the product standard $\bar{g}$ and a duopoly with simultaneous moves, the solution is the following:

$$
\begin{aligned}
& \text { (i) If } \bar{g} \leq \frac{0,07 \bar{\gamma}^{2}}{\alpha} \text {, then } p_{1}^{D}=\frac{0,091 \bar{\gamma}^{3}}{\alpha}, g_{1}^{D}=\frac{0,24 \bar{\gamma}^{2}}{\alpha}, p_{2}^{D}=\frac{0,013 \bar{\gamma}^{3}}{\alpha} \text {, and } g_{2}^{D}= \\
& \frac{0,07 \bar{\gamma}^{2}}{\alpha} \text {. } \\
& \text { (ii) If } \quad \frac{0,07 \bar{\gamma}^{2}}{\alpha} \quad \leq \quad \frac{0,22 \bar{\gamma}^{2}}{\alpha}, \quad \text { then } p_{1}^{D}= \\
& \frac{\left[2 \alpha \bar{g}+\bar{\gamma}^{2}+\bar{\gamma}\left(\bar{\gamma}^{2}-4 \alpha \bar{g}\right)^{1 / 2}\right]\left[\bar{\gamma}^{2}-6 \alpha \bar{g}+\bar{\gamma}\left(\bar{\gamma}^{2}-4 \alpha \bar{g}\right)^{1 / 2}\right]}{16 \alpha\left[\bar{\gamma}+\left(\bar{\gamma}^{2}-4 \alpha \bar{g}\right)^{1 / 2}\right]}, g_{1}^{D}=\frac{2 \alpha \bar{g}+\bar{\gamma}^{2}+\bar{\gamma}\left(\bar{\gamma}^{2}-4 \alpha \bar{g}\right)^{1 / 2}}{8 \alpha}, \\
& p_{2}^{D}=\frac{\bar{g}\left[\bar{\gamma}^{2}-6 \alpha \bar{g}+\bar{\gamma}\left(\bar{\gamma}^{2}-4 \alpha \bar{g}\right)^{1 / 2}\right]}{4\left[\bar{\gamma}+\left(\bar{\gamma}^{2}-4 \alpha \bar{g}\right)^{1 / 2}\right]} \text {, and } g_{2}^{D}=\bar{g} .
\end{aligned}
$$

(iii) If $\bar{g} \geq \frac{0,22 \bar{\gamma}^{2}}{\alpha}$, then $p_{1}^{D}=p_{2}^{D}=0$ and $g_{1}^{D}=g_{2}^{D}=\bar{g}$. 
Fig. 5 Product standards under duopoly

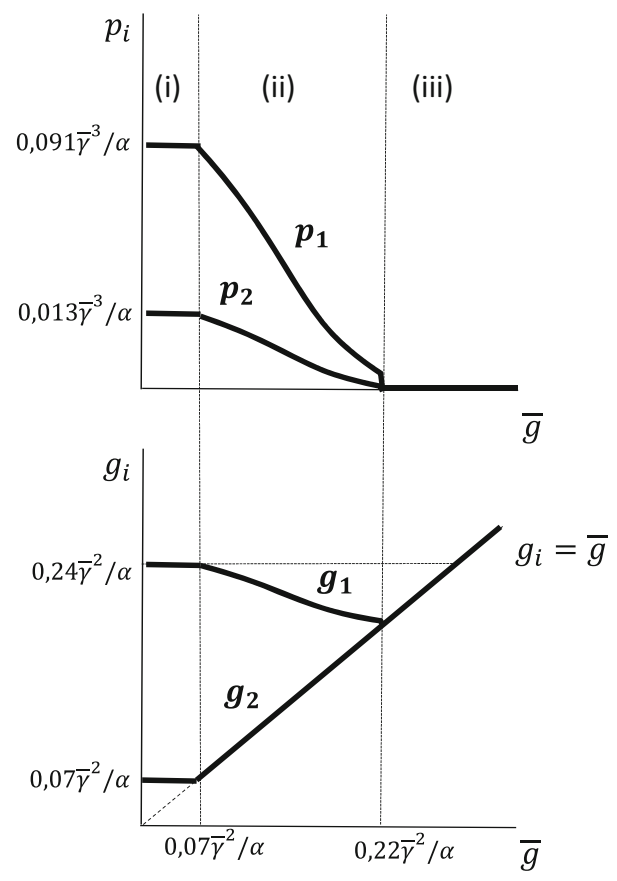

We present the result in Fig. 5. The three cases presented in the proposition are clearly identified in the figure. In case (i), the two firms over-comply with the standard; in case (ii), firm 2 just complies, while firm 1 over-complies. Finally, in case (iii) the two firms just comply. Case (ii) is interesting because firm 1 reacts to the fact that firm 2 has to comply with the standard. There are two effects working in opposite directions. On the one hand, firm 1 has an incentive to increase its energy efficiency level as long as $\bar{g}$ increases, to maintain the difference between the two firms, which positively affects prices and revenues. On the other hand, increasing the energy efficiency level increases the corresponding costs. In our setting, the net effect is negative, which means that as long as the product standard increases, firm 1 decreases its corresponding energy efficiency level, until the two firms end up just complying with the standard. In fact, this negative effect of $\bar{g}$ on $g_{1}^{D}$ can be checked by taking the corresponding partial derivative:

$$
\frac{\partial g_{1}^{D}}{\partial \bar{g}}=\frac{1}{4}\left(1-\frac{\bar{\gamma}}{\left(\bar{\gamma}^{2}-4 \alpha \bar{g}\right)^{1 / 2}}\right)
$$

which is negative, since $\bar{\gamma}>\left(\bar{\gamma}^{2}-4 \alpha \bar{g}\right)^{1 / 2}$.

Hence, as long as the product standard increases, the differentiation between the two firms diminishes. This has a negative effect on the prices, which end up being zero in region (iii), that is, when the two firms just comply with the standard and, therefore, supply identical products. Comparing Fig. 5 with Fig. 1, we see that the presence of a product standard has very different effects depending on the market structure. While a 
more demanding standard always induces an increase in the energy efficiency level in the monopoly case, in a duopoly the imposition of a standard has a detrimental effect on the most energy-efficient firm. As a result, the effect on the prices is completely the opposite. While an increase in the standard always induces a price increase under monopoly, an increase in the standard induces a decrease in the prices of the two varieties under duopoly, until they reach zero prices. Under this situation, profits for the firms are negative (zero revenues minus the costs of being green), which suggests that a duopoly cannot be sustained in region (iii).

This interesting result contrasts with the one found in Moraga-González and PadrónFumero (2002), see their Lemma 2 on page 428. They consider the imposition of an emission standard, which is met by one of the firms, and further induce a reduction in the emission level of the rival firm. Thus, the imposition of the standard causes an effect in the same direction on both firms. In our context, however, we find opposing effects that diminish differentiation and end up in zero prices. The main difference between the two settings is that they consider a model of sequential moves, while we consider a model of simultaneous decisions. ${ }^{7}$

We now turn to analyze crowding-in and crowding-out effects in this context. Remember that we model crowding-in (out) by assuming that $\bar{\gamma}$ is an increasing (decreasing) function of $\bar{g}$. In the monopoly case, we find that the effect of the product standard is reinforced (diminished) under crowding-in (out). Here, we obtain a similar finding, since $g_{1}^{D}$ clearly increases with $\bar{\gamma}$, but the overall effect in the market needs to be qualified. Again, the interesting region is the one where firm 2 just complies with the standard while firm 1 over-complies. Under crowding-out, firm 2 continues to comply in this region, but the efficiency level of firm 1 decreases. Crowding-out then decreases the differentiation gap between the two firms and, as a consequence, reduces prices of the two firms. The threshold level of the standard above which the duopoly cannot be sustained is lower when crowding-out is present. Crowding-in has exactly the opposite effect than crowding-out, and hence, the differentiation gap between the two rivals in the interesting region is wider. However, due to the negative effect of the product standard on firm 1, there can be a region where an increase in the product standard may end up having a net negative effect on the energy efficiency level of firm 1. This interesting finding is illustrated in Fig. 6, where we can see that the efficiency level of firm 1 lies below the laissez-faire level $\left(0.24 \bar{\gamma}^{2} / \alpha\right)$ for a subset of values of the product standard, $\bar{g}$.

\subsubsection{Technology subsidy}

In the duopoly case, a technology subsidy (represented by a decrease in parameter $\alpha$ ) results in an increase in the energy efficiency level and the product price of the two varieties. This can be easily seen by looking at the corresponding expressions presented in Propositions 3 and 4. In fact, both the differences in energy efficiency levels and prices increase as the amount of the subsidy increases (when $\alpha$ decreases) in the two cases of simultaneous moves and sequential choices. Thus, while the product standard

\footnotetext{
7 If we instead consider the imposition of a product standard in the model of sequential choices presented in Proposition 4, we obtain the same result as Moraga-Gonzalez and Padron-Fumero (2002).
} 
Fig. 6 Product standards and crowding-in under duopoly

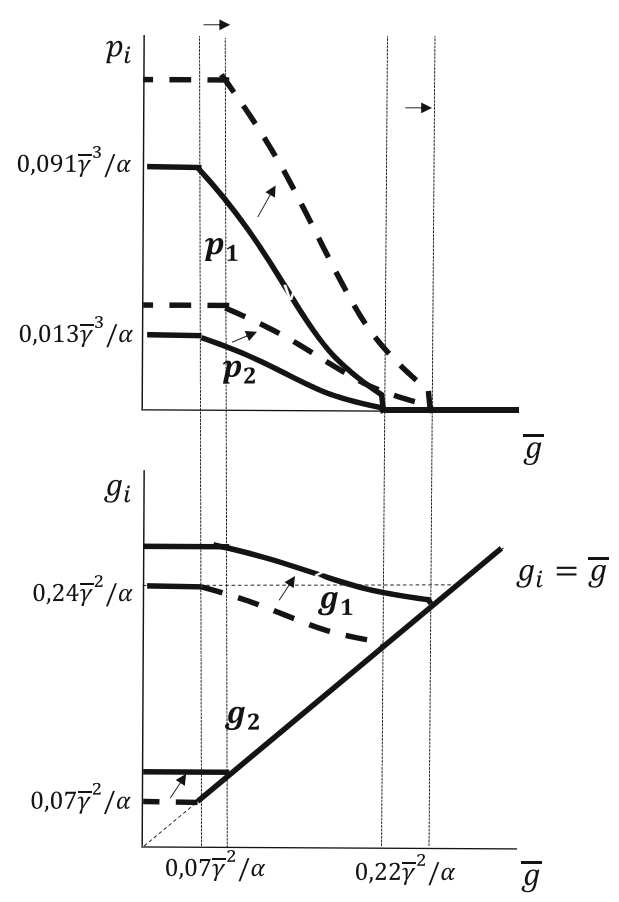

generated opposite effects when comparing the two market structures (monopoly and duopoly), a technology subsidy induces qualitatively similar effects under the two market structures. In particular, the use of a subsidy under severe crowding-out in the duopolistic setting can be detrimental for energy efficiency as well.

\section{Conclusions}

The transition toward a sustainable and zero-carbon economic system provides businesses with many challenges, and a broad set of actions is necessary. One such action is energy-efficient product design. Households are increasingly aware of the societal impacts of their consumption choices. As consumers become more sensitive to the environmental impact of specific product characteristics, businesses adapt their product and service mixes. Besides business responses to consumer awareness, governments also introduce more-and more stringent—environmental regulations. We believe that product design, consumer awareness, and regulation have to be studied simultaneously to account for interactions and feedback effects. For this reason, we have developed a model to investigate the effect of education, product standards, and technology subsidies on energy-related product characteristics while allowing for crowding-in or crowding-out via consumers' preferences. The different scenarios have provided the following set of insights.

Firstly, explicitly modeling energy-efficient design in a monopoly market provides the firm with an additional way to extract rents from consumers. Thus, even without 
regulation, the firm has an incentive to invest in energy efficiency of the product. This can be seen as a good thing if energy-efficient product design is underprovided from a social point of view. The firm thus automatically reacts to changing societal trends and increasing consumers' awareness. Introducing competition in the market (through a duopoly) leads to product differentiation where, depending on the timing of the decisions, one of the firms can be incentivized to invest more in an energy-efficient design than in a monopoly setting, even with lower prices.

Secondly, regulatory instruments influence energy-efficient product design in a direct way, but also in an indirect way through consumers' awareness. The indirect effect can reinforce or counteract the direct effect of regulation. The net effect does not only depend on the size of crowding-out or crowding-in of consumers' intrinsic motivation to buy green, but also on the type of policy instrument that is used. A policy based on a product standard can counteract the negative effects of crowdingout consumers' intrinsic motivation. A subsidy does not provide such a backup system, and the full effect of crowding-out might be visible. In fact, there can be instances in which implementing a technology subsidy can be fully detrimental for energy efficiency.

Thirdly, the presence of a product standard has very different effects depending on the market structure. While a more demanding standard always leads to a more energyefficient product in the monopoly case, the standard can have a negative effect on the environmental impact of the product design selected by the most energy-efficient firm in a duopoly. In the most extreme situation, the imposition of strict energy-efficient product standards can force one firm out of the market and thus reduce competition.

Based on these insights, we want to highlight several extensions that are worth considering. Firstly, regarding our assumptions, we have considered that a product's energy efficiency level does no directly impact its unit production costs. However, it is plausible that a more energy-efficient design makes the production more costly (e.g., adding sensors or electronic time clocks) or less costly (e.g., making a product lighter implies lower material usage). Also, reducing the amount of embedded carbon in a product, e.g., by using solar or wind energy, can shift marginal production costs downward. Thus, it would be interesting to study the interaction effects between product design, short-term unit production costs, and long-term operation costs. Secondly, we have considered zero reservation utility for the option of not purchasing the product, but one may wonder what would happen if the reservation utility were affected by the regulation. This may constitute an interesting area of research, because, even in the monopoly case, the effects of the reservation utility on both energy efficiency and the product price are ambiguous. ${ }^{8}$ Thirdly, the model would become more realistic

\footnotetext{
${ }^{8}$ For reservation utility $\bar{U} \neq 0$, only consumers with marginal willingness to pay $\gamma$ such that $\gamma g-p \geq \bar{U}$ would purchase the product, and the aggregate demand function in this case would be $Q=\bar{\gamma}-\frac{\bar{U}+p}{g}$. If we consider the monopolist's optimization problem (as in (3)) for this demand function, we obtain that the optimal energy efficiency level and product price are implicitly given by the expressions $4 \alpha g^{3}-\bar{\gamma}^{2} g^{2}+\bar{U}^{2}=$ 0 and $p=\frac{\bar{\gamma} g-\bar{U}}{2}$. There is an unambiguous negative effect of the reservation utility on both the energy efficiency level and the product price as long as the optimal energy efficiency level is larger than $\bar{\gamma}^{2} / 6 \alpha$. However, for the alternative case, a change in the reservation utility has a positive effect on the energy efficiency level and an ambiguous effect on the product price. Additional ambiguities can be found in the more complex duopolistic situations.
} 
by allowing a heterogeneous cost structure. Differences in production costs may lead to differences in production quantities or product prices with the most efficient firm producing the most (or charging the lowest price) and the least efficient firm producing the least (or charging the highest price) (see, for example, Wang and Zhao 2009). In addition, one may analyze a setting where there is one installed firm and a potential incumbent. This timing is different from the ones we have analyzed in the paper, since the installed firm would choose both the energy efficiency level and the product price in the first place. This alternative modeling may raise interesting issues regarding the possibility to accommodate or deter entry, which are beyond the scope of the present study.

Further, it would be interesting to investigate the full welfare effects of the different policy scenarios including implementation costs such as costs of educational reforms, advertising campaigns, administrative costs, and monitoring activities as well as the net effect on environmental quality. Based on the calculation of the welfare effects, the regulator would then be able to choose the most desirable policy option, while taking the reaction of firms and households into account.

Finally, note that we only investigate one option to make our economic and energy system more sustainable, but several other options are available. An interesting evolution is the move toward product-service system or even full servitization within the transition to a circular economy. Policymakers are increasingly aware of the importance to coordinate climate and circular economy policy actions to achieve a more sustainable economic system.

Funding This study was founded by the Ministry of Economy and Competitiveness under research project N. ECO2017-82449-P.

\section{Compliance with ethical standards}

Conflict of interest Carmen Arguedas declares that he/she has no conflict of interest. Sandra Rousseau declares that he/she has no conflict of interest.

Ethical approval This article does not contain any studies with human participants or animals performed by any of the authors.

Open Access This article is licensed under a Creative Commons Attribution 4.0 International License, which permits use, sharing, adaptation, distribution and reproduction in any medium or format, as long as you give appropriate credit to the original author(s) and the source, provide a link to the Creative Commons licence, and indicate if changes were made. The images or other third party material in this article are included in the article's Creative Commons licence, unless indicated otherwise in a credit line to the material. If material is not included in the article's Creative Commons licence and your intended use is not permitted by statutory regulation or exceeds the permitted use, you will need to obtain permission directly from the copyright holder. To view a copy of this licence, visit http://creativecommons.org/licenses/by/4.0/.

\section{Appendix}

Proof of Proposition 3 The first-order conditions of the two problems characterize the solution: 


$$
\begin{aligned}
\frac{\partial \pi_{1}}{\partial p_{1}} & =\bar{\gamma}-\frac{2 p_{1}}{g_{1}-g_{2}}+\frac{p_{2}}{g_{1}-g_{2}}=0, \\
\frac{\partial \pi_{1}}{\partial g_{1}} & =\frac{p_{1}\left(p_{1}-p_{2}\right)}{\left(g_{1}-g_{2}\right)^{2}}-\alpha g_{1}=0, \\
\frac{\partial \pi_{2}}{\partial p_{2}} & =\frac{p_{1} g_{2}-2 p_{2} g_{1}}{g_{2}\left(g_{1}-g_{2}\right)}=0, \\
\frac{\partial \pi_{2}}{\partial g_{2}} & =p_{2} \frac{p_{1} g_{2}\left(g_{1}-g_{2}\right)-\left(p_{1} g_{2}-p_{2} g_{1}\right)\left(g_{1}-2 g_{2}\right)}{g_{2}^{2}\left(g_{1}-g_{2}\right)^{2}}-\alpha g_{2}=0 .
\end{aligned}
$$

From the first and third conditions, we, respectively, obtain $p_{1}=\frac{\bar{\gamma}\left(g_{1}-g_{2}\right)+p_{2}}{2}$ and $p_{2}=\frac{p_{1} g_{2}}{2 g_{1}}$, from which we easily get $p_{1}=\frac{2 g_{1} \bar{\gamma}\left(g_{1}-g_{2}\right)}{4 g_{1}-g_{2}}$ and $p_{2}=\frac{g_{2} \bar{\gamma}\left(g_{1}-g_{2}\right)}{4 g_{1}-g_{2}}$.On the one hand, the fourth first-order condition can be simplified as $p_{2} \frac{p_{1} g_{2}^{2}+p_{2} g_{1}^{2}-2 p_{2} g_{1} g_{2}}{g_{2}^{2}\left(g_{1}-g_{2}\right)^{2}}-$ $\alpha g_{2}=0$, and we can substitute expressions $p_{1}=\frac{2 g_{1} \bar{\gamma}\left(g_{1}-g_{2}\right)}{4 g_{1}-g_{2}}$ and $p_{2}=\frac{g_{2} \bar{\gamma}\left(g_{1}-g_{2}\right)}{4 g_{1}-g_{2}}$ in there, to obtain:

$$
\bar{\gamma}^{2} g_{1}^{2}=\alpha g_{2}\left(4 g_{1}-g_{2}\right)^{2}
$$

On the other hand, we can substitute $p_{1}=\frac{2 g_{1} \bar{\gamma}\left(g_{1}-g_{2}\right)}{4 g_{1}-g_{2}}$ and $p_{2}=\frac{g_{2} \bar{\gamma}\left(g_{1}-g_{2}\right)}{4 g_{1}-g_{2}}$ in the second first-order condition, to obtain:

$$
2 \bar{\gamma}^{2}\left(2 g_{1}-g_{2}\right)=\alpha\left(4 g_{1}-g_{2}\right)^{2} .
$$

Combining these two resulting conditions, we have $\frac{g_{1}^{2}}{g_{2}}=2\left(2 g_{1}-g_{2}\right)$, or put differently, $g_{1}^{2}+2 g_{2}^{2}-4 g_{1} g_{2}=0$. This expression is equivalent to $g_{1}^{2}+4 g_{2}^{2}-4 g_{1} g_{2}=2 g_{2}^{2}$, that is, $\left(g_{1}-2 g_{2}\right)^{2}=2 g_{2}^{2}$, which yields $g_{1}=(2+\sqrt{2}) g_{2}=3,41 g_{2}$. Substituting this condition into $\bar{\gamma}^{2} g_{1}^{2}=\alpha g_{2}\left(4 g_{1}-g_{2}\right)^{2}$, we obtain two candidate solutions: $g_{2}^{D}=\frac{0,07 \bar{\gamma}^{2}}{\alpha}<g^{M}$ and $g_{1}^{D}=\frac{0,24 \bar{\gamma}^{2}}{\alpha}<g^{M}$; or $g_{1}^{D}=g_{2}^{D}=0$. We concentrate on the first possibility. (The second leads to no green effort and zero profits and, hence, it is not interesting.) We use conditions $p_{1}=\frac{2 g_{1} \bar{\gamma}\left(g_{1}-g_{2}\right)}{4 g_{1}-g_{2}}$ and $p_{2}=\frac{g_{2} \bar{\gamma}\left(g_{1}-g_{2}\right)}{4 g_{1}-g_{2}}$ to obtain the respective equilibrium prices in the duopoly case:

$$
\begin{aligned}
& p_{1}^{D}=\frac{2\left(\frac{0,24 \bar{\gamma}^{2}}{\alpha}\right) \bar{\gamma}\left(\frac{0,24 \bar{\gamma}^{2}}{\alpha}-\frac{0,07 \bar{\gamma}^{2}}{\alpha}\right)}{4\left(\frac{0,24 \bar{\gamma}^{2}}{\alpha}\right)-\frac{0,07 \bar{\gamma}^{2}}{\alpha}}=\frac{0,091 \bar{\gamma}^{3}}{\alpha}<p^{M}, \\
& p_{2}^{D}=\frac{\left(\frac{0,07 \bar{\gamma}^{2}}{\alpha}\right) \bar{\gamma}\left(\frac{0,24 \bar{\gamma}^{2}}{\alpha}-\frac{0,07 \bar{\gamma}^{2}}{\alpha}\right)}{4\left(\frac{0,24 \bar{\gamma}^{2}}{\alpha}\right)-\frac{0,07 \bar{\gamma}^{2}}{\alpha}}=\frac{0,013 \bar{\gamma}^{3}}{\alpha}<p^{M} .
\end{aligned}
$$


Proof of Proposition 4 We start by solving the second stage of the problem (which consists of taking the first-order derivative of each profit function with respect to the respective price):

$$
\begin{aligned}
& \frac{\partial \pi_{1}}{\partial p_{1}}=\bar{\gamma}-\frac{2 p_{1}}{g_{1}-g_{2}}+\frac{p_{2}}{g_{1}-g_{2}}=0, \\
& \frac{\partial \pi_{2}}{\partial p_{2}}=\frac{p_{1} g_{2}-2 p_{2} g_{1}}{g_{2}\left(g_{1}-g_{2}\right)}=0
\end{aligned}
$$

from which we obtain prices as functions of the two energy efficiency levels, $p_{1}=$ $\frac{2 g_{1} \bar{\gamma}\left(g_{1}-g_{2}\right)}{4 g_{1}-g_{2}}$ and $p_{2}=\frac{g_{2} \bar{\gamma}\left(g_{1}-g_{2}\right)}{4 g_{1}-g_{2}}$, as in the previous case. We substitute these two expressions in the respective profit functions to obtain:

$$
\begin{aligned}
& \pi_{1}=\frac{4 \bar{\gamma}^{2} g_{1}^{2}\left(g_{1}-g_{2}\right)}{\left(4 g_{1}-g_{2}\right)^{2}}-\frac{\alpha}{2} g_{1}^{2}, \\
& \pi_{2}=\frac{\bar{\gamma}^{2} g_{1} g_{2}\left(g_{1}-g_{2}\right)}{\left(4 g_{1}-g_{2}\right)^{2}}-\frac{\alpha}{2} g_{2}^{2},
\end{aligned}
$$

and we now take the partial derivative of profits with respect to the respective energy efficiency levels, as follows:

$$
\begin{aligned}
& \frac{\partial \pi_{1}}{\partial g_{1}}=\frac{4 \bar{\gamma}^{2}}{\left(4 g_{1}-g_{2}\right)^{4}}\left\{\left(3 g_{1}^{2}-2 g_{1} g_{2}\right)\left(4 g_{1}-g_{2}\right)^{2}-8\left(g_{1}^{3}-g_{1}^{2} g_{2}\right)\left(4 g_{1}-g_{2}\right)\right\}-\alpha g_{1}=0, \\
& \frac{\partial \pi_{2}}{\partial g_{2}}=\frac{\bar{\gamma}^{2} g_{1}}{\left(4 g_{1}-g_{2}\right)^{4}}\left\{\left(g_{1}-2 g_{2}\right)\left(4 g_{1}-g_{2}\right)^{2}+2 g_{2}\left(g_{1}-g_{2}\right)\left(4 g_{1}-g_{2}\right)\right\}-\alpha g_{2}=0 .
\end{aligned}
$$

From these two conditions, we, respectively, get:

$$
\begin{aligned}
& 4\left\{\left(3 g_{1}-2 g_{2}\right)\left(4 g_{1}-g_{2}\right)-8\left(g_{1}^{2}-g_{1} g_{2}\right)\right\}=\frac{\alpha\left(4 g_{1}-g_{2}\right)^{3}}{\bar{\gamma}^{2}} . \\
& \frac{g_{1}}{g_{2}}\left\{\left(g_{1}-2 g_{2}\right)\left(4 g_{1}-g_{2}\right)+2 g_{2}\left(g_{1}-g_{2}\right)\right\}=\frac{\alpha\left(4 g_{1}-g_{2}\right)^{3}}{\bar{\gamma}^{2}} .
\end{aligned} .
$$

Now, we combine these two expressions to have:

$$
\begin{aligned}
& 4\left\{\left(3 g_{1}-2 g_{2}\right)\left(4 g_{1}-g_{2}\right)-8\left(g_{1}^{2}-g_{1} g_{2}\right)\right\} \\
& =\frac{g_{1}}{g_{2}}\left\{\left(g_{1}-2 g_{2}\right)\left(4 g_{1}-g_{2}\right)+2 g_{2}\left(g_{1}-g_{2}\right)\right\},
\end{aligned}
$$

and we conjecture $g_{1}=\beta g_{2}$ for the solution. Note that following this procedure, one possible solution is always $g_{1}=g_{2}=0$ (which is not interesting). We concentrate in the interior solution, which results in: $4\{(3 \beta-2)(4 \beta-1)-8 \beta(\beta-1)\}=\beta$ $\{(\beta-2)(4 \beta-1)+2 \beta-2\}$, from which we obtain $; 4 \beta^{3}-23 \beta^{2}+12 \beta-8=0$, and a unique real solution (there are two additional imaginary solutions), $\beta=5,25$. This therefore means that $g_{1}=5,25 g_{2}$. We now go back to the first above expression and substitute $g_{1}=5,25 g_{2}$ to obtain: 


$$
g_{2}^{S}=\frac{0,05 \bar{\gamma}^{2}}{\alpha}<g^{M} \text { and } g_{1}^{S}=\frac{0,26 \bar{\gamma}^{2}}{\alpha}>g^{M}
$$

Following a similar procedure as before, we now substitute equilibrium energy efficiency levels in the corresponding expressions for the prices and the aggregate demands, and we obtain: $p_{1}^{S}=\frac{0,11 \bar{\gamma}^{3}}{\alpha}<p^{M}, p_{2}^{S}=\frac{0,01 \bar{\gamma}^{3}}{\alpha}<p^{M}, Q_{1}^{S}=0,53 \bar{\gamma}$ and $Q_{2}^{S}=0,26 \bar{\gamma}$, which results in respective equilibrium profits: $\pi_{1}^{S}=\frac{0,0245 \bar{\gamma}^{4}}{\alpha}<\pi^{M}$ and $\pi_{2}^{S}=\frac{0,0013 \bar{\gamma}^{4}}{\alpha}<\pi^{M}$.

Proof of Proposition 5 Here, we prove case (ii), because case (i) has been proven in Proposition 3 (in this case, the standard is very weak and does not affect the laissezfaire solution), and case (iii) follows directly from the explanation of case (ii) in the upper part of the interval. When $\bar{g} \geq \frac{0,07 \bar{\gamma}^{2}}{\alpha}$, firm 2 just complies with the standard. The first-order conditions of this problem coincide with the first three conditions of Proposition 3 when $g_{2}=\bar{g}$, presented in the corresponding proof above, that is:

$$
\begin{aligned}
& \frac{\partial \pi_{1}}{\partial p_{1}}=\bar{\gamma}-\frac{2 p_{1}}{g_{1}-\bar{g}}+\frac{p_{2}}{g_{1}-\bar{g}}=0, \\
& \frac{\partial \pi_{1}}{\partial g_{1}}=\frac{p_{1}\left(p_{1}-p_{2}\right)}{\left(g_{1}-\bar{g}\right)^{2}}-\alpha g_{1}=0, \\
& \frac{\partial \pi_{2}}{\partial p_{2}}=\frac{p_{1} \bar{g}-2 p_{2} g_{1}}{g_{2}\left(g_{1}-\bar{g}\right)}=0 .
\end{aligned}
$$

From the first and third conditions, we can get the respective prices as a function of $g_{1}$ and $\bar{g}$, exactly as in the proof of Proposition 3, that is, $p_{1}=\frac{2 g_{1} \bar{\gamma}\left(g_{1}-\bar{g}\right)}{4 g_{1}-\bar{g}}$ and $p_{2}=\frac{\bar{g} \bar{\gamma}\left(g_{1}-\bar{g}\right)}{4 g_{1}-\bar{g}}$. Now, we substitute these two expressions in the second first-order condition, and we obtain:

$$
2 \bar{\gamma}^{2}\left(2 g_{1}-\bar{g}\right)=\alpha\left(4 g_{1}-\bar{g}\right)^{2} .
$$

From this condition, we get two candidates for the solution: $g_{1}=\frac{2 \alpha \bar{g}+\bar{\gamma}^{2} \pm \bar{\gamma}\left(\bar{\gamma}^{2}-4 \alpha \bar{g}\right)^{1 / 2}}{8 \alpha}$. Since $g_{1}$ must be strictly larger than $\bar{g}$, the solution must be $g_{1}=\frac{2 \alpha \bar{g}+\bar{\gamma}^{2}+\bar{\gamma}\left(\bar{\gamma}^{2}-4 \alpha \bar{g}\right)^{1 / 2}}{8 \alpha}$, for $\bar{g}<\frac{0,22 \bar{\gamma}^{2}}{\alpha}$. This limiting value of $\bar{g}$ comes from substituting a value of $g_{1}$ sufficiently close (but larger) than $\bar{g}$ into the implicit expression $2 \bar{\gamma}^{2}\left(2 g_{1}-\bar{g}\right)=\alpha$ $\left(4 g_{1}-\bar{g}\right)^{2}$ to obtain $2 \bar{\gamma}^{2} \bar{g}=\alpha(3 \bar{g})^{2}$, from which we get $\bar{g}=\frac{2 \bar{\gamma}^{2}}{9 \alpha}=\frac{0,22 \bar{\gamma}^{2}}{\alpha}$. Finally, we obtain the equilibrium prices by substituting this solution into the respective expressions. 


\section{References}

Anderson B, Böhmelt T, Ward H (2017) Public opinion and environmental policy output: a cross-national analysis of energy policies in Europe. Environ Res Lett 12(11):114011

Asheim GB (2010) Strategic use of environmental information. Environ Resource Econ 46(2):207-216

Casino B, Granero L (2018) Sustainable products, market structure, and welfare. In: Paper presented at annual FAERE conference, 30-31 August 2018, Aix-en-Provence, France. Accessed 10 Jan 2020

Chu S, Majumdar A (2012) Opportunities and challenges for a sustainable energy future. Nature 488(7411):294-303

EEB (2019) Newly approved energy labels can transform the way we shop. https://eeb.org/newly-approvedenergy-labels-can-transform-the-way-we-shop/. Accessed 10 Jan 2020

Espinola-Arredondo A, Zhao H (2012) Environmental policy in a linear city model of product differentiation. Environ Dev Econ 17(4):461-477

European Commission (2019) Sustainable products in a circular economy-towards an EU product policy framework contributing to the circular economy. Commission Staff Working Document SWD (2019) 92 final. https://ec.europa.eu/environment/circular-economy/pdf/sustainable_products_ circular_economy.pdf. Accessed 10 Jan 2020

Firestone J, Kempton W, Lilley MB, Samoteskul K (2012) Public acceptance of offshore wind power across regions and through time. J Environ Plan Manag 55(10):1369-1386

Frey BS, Götte L (1999) Does pay motivate volunteers? Working paper/Institute for Empirical Research in Economics, https://doi.org/10.3929/ethz-a-004372692. Accessed 10 Jan 2020

Frey BS, Oberholzer-Gee F (1997) The cost of price incentives: an empirical analysis of motivation crowding-out. Am Econ Rev 87(4):746-755

Friends of the Earth (2010) Energy savings: overview of NGO views for the forthcoming energy efficiency action plan.www.foeeurope.org/sites/default/files/ngo_views_on_energy_efficiency_needs_nov2010 1.pdf. Accessed 10 Jan 2020

Fullerton D, Wu W (1998) Policies for energy efficient design. J Environ Econ Manag 36(2):131-148

Geer JG (1996) From tea leaves to opinion polls: a theory of democratic leadership. Columbia University Press, Columbia

Gillingham K, Rapson D, Wagner G (2016) The rebound effect and energy efficiency policy. Rev Environ Econ Policy 10(1):68-88

Hakhverdian A (2012) The causal flow between public opinion and policy: government responsiveness, leadership, or counter movement? West Eur Politics 35(6):1386-1406

Kennedy PW, Laplante B, Maxwell J (1994) Pollution policy: the role for publicly provided information. J Environ Econ Manag 26(1):31-43

Kreps DM (1997) Intrinsic motivation and extrinsic incentives. Am Econ Rev 87(2):359-364

Moraga-Gonzalez JL, Padron-Fumero N (2002) Environmental policy in a green market. Environ Resource Econ 22(3):419-447

Morini AA, Ribeiro MJ, Hotza D (2019) Early-stage materials selection based on embodied energy and carbon footprint. Mater Des 178:107861

Nyborg K (2018) Social norms and the environment. Annu Rev Resour Econ 10:405-423

Nyborg K, Rege M (2003) Does public policy crowd out private contributions to public goods. Public Choice 115(3-4):397-418

Olson-Hazboun SK, Krannich RS, Robertson PG (2016) Public views on renewable energy in the Rocky Mountain region of the United States: distinct attitudes, exposure, and other key predictors of wind energy. Energy Res Soc Sci 21:167-179

Rahimifard S, Seow Y, Childs T (2010) Minimising embodied product energy to support energy efficient manufacturing. CIRP Ann 59(1):25-28

Raworth K (2017) Doughnut economics - seven ways to think like a 21st-century economist. Ed. Cornerstone/Cornerstone Ras, pp 384, ISBN 9781847941374

Ribot J (2013) Vulnerability does not just fall from the sky: Toward multi-scale pro-poor climate policy. In: Handbook on climate change and human security. Edward Elgar Publishing

Rodriguez-Ibeas R (2007) Environmental product differentiation and environmental awareness. Environ Resource Econ 36:237-254

Stadelmann-Steffen I, Eder C (2020) Public opinion in policy contexts A comparative analysis of domestic energy policies and individual policy preferences in Europe. Int Political Sci Rev 25:10. https://doi. org/10.1177/0192512120913047 
Sterner T (ed) (2012) Fuel taxes and the poor: the distributional effects of gasoline taxation and their implications for climate policy. Routledge, New York

Stokes LC (2013) The politics of renewable energy policies: the case of feed-in tariffs in Ontario, Canada. Energy Policy 56:490-500

Underhill K (2016) When extrinsic incentives displace intrinsic motivation: designing legal carrots and sticks to confront the challenge of motivational crowding-out. Yale J Regul 33(1):213-280

Vivanco DF, Kemp R, van der Voet E (2016) How to deal with the rebound effect? A policy-oriented approach. Energy Policy 94:114-125

Wang XH, Zhao J (2009) On the efficiency of indirect taxes in differentiated oligopolies with asymmetric costs. J Econ 96(3):223-239

Wlezien C, Soroka SN (2012) Political institutions and the opinion-policy link. West Eur Politics 35(6):1407-1432

World Economic Forum (2012) Energy for economic growth-Energy vision update 2012. www3.weforum. org/docs/WEF_EN_EnergyEconomicGrowth_IndustryAgenda_2012.pdf. Accessed 10 Jan 2020

Publisher's Note Springer Nature remains neutral with regard to jurisdictional claims in published maps and institutional affiliations. 